\title{
Total Sky Imager Handbook
}

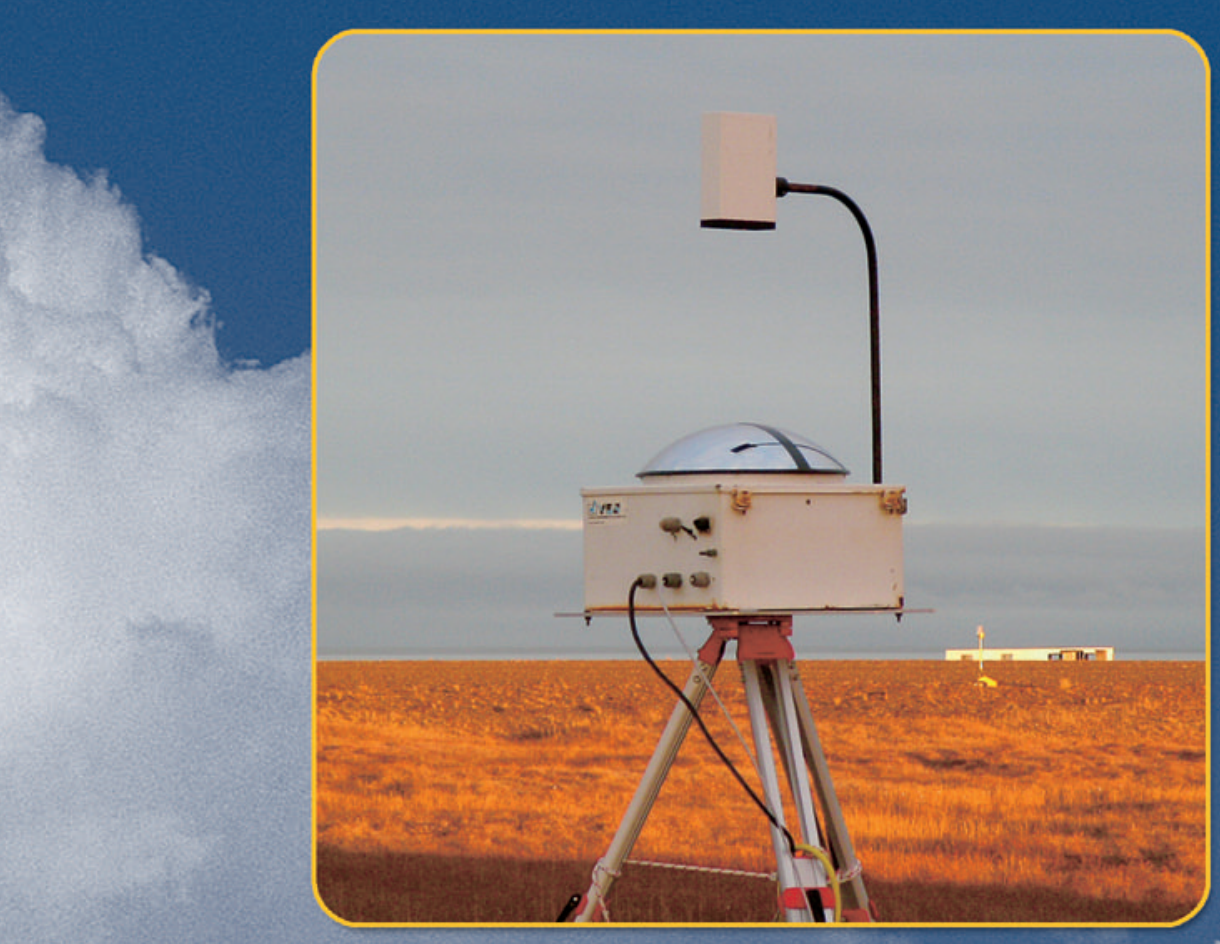

\section{June 2005}

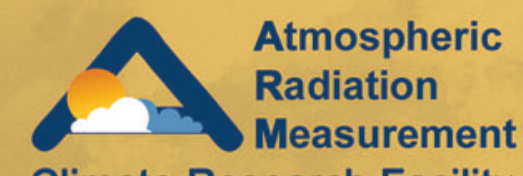

Climate Research Facility

U.S. Department of Energy 


\section{Total Sky Imager (TSI) Handbook}

June 2005

V. R. Morris

Work supported by the U.S. Department of Energy, Office of Science, Office of Biological and Environmental Research 


\section{Contents}

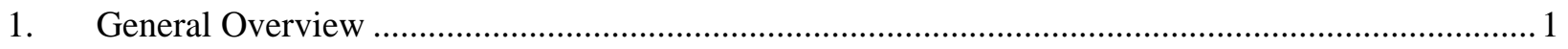

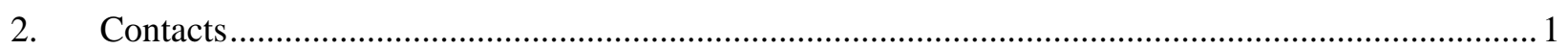

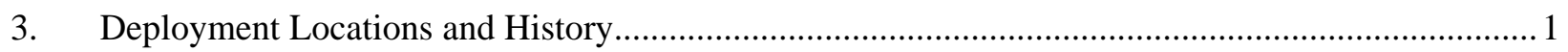

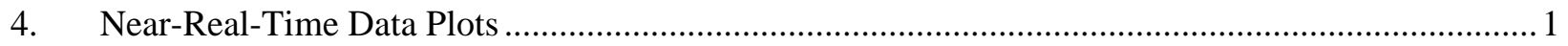

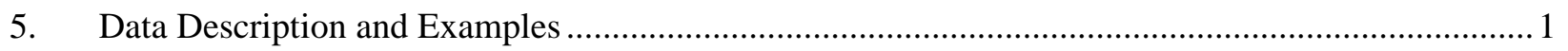

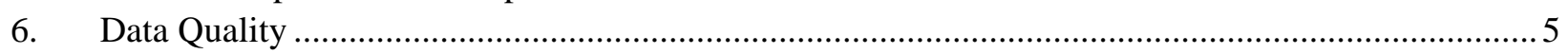

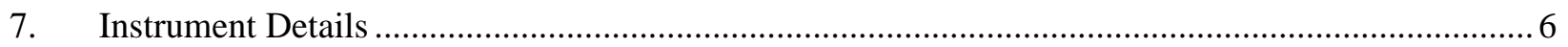

Tables

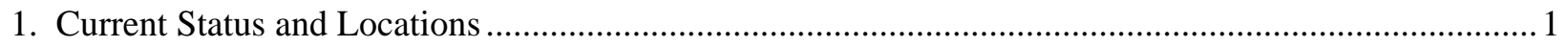

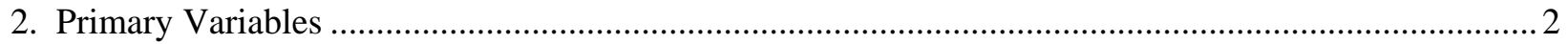

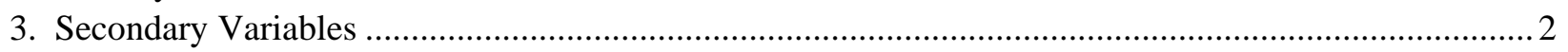

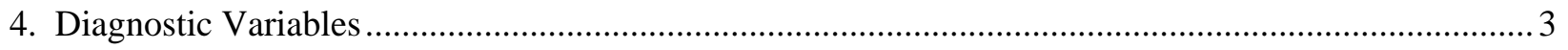

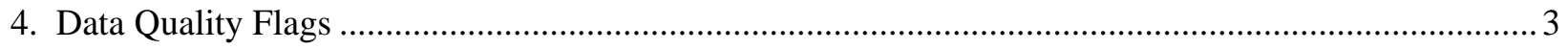

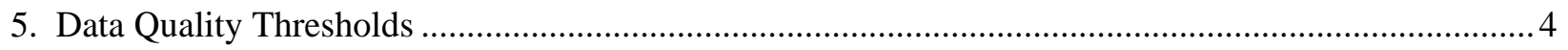

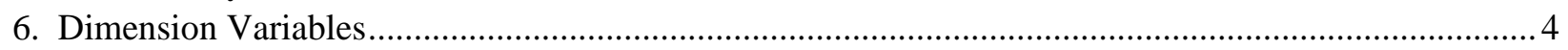

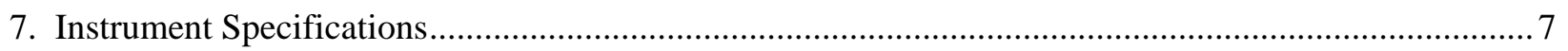




\section{General Overview}

The total sky imager (TSI) provides time series of hemispheric sky images during daylight hours and retrievals of fractional sky cover for periods when the solar elevation is greater than 10 degrees.

\section{Contacts}

\subsection{Mentor}

Victor Morris

Pacific Northwest National Laboratory

P.O. Box 999, MS K9-24

Richland, WA 99352

Phone: 509-372-6144

Fax: 509-372-6268

Email: victor.morris@pnl.gov

\subsection{Instrument Developer}

Yankee Environmental Systems (YES), Inc.

101 Industrial Blvd.

Turners Falls, MA 01376

Phone: 413-863-0200, ext. 7201

Fax: 413-863-0255

Website: http://www.yesinc.com

\section{Deployment Locations and History}

Table 1. Current Status and Locations

\begin{tabular}{|c|c|c|c|c|}
\hline $\begin{array}{c}\text { Serial } \\
\text { Number }\end{array}$ & $\begin{array}{c}\text { Property } \\
\text { Number }\end{array}$ & Location & $\begin{array}{c}\text { Installation } \\
\text { Date }\end{array}$ & Status \\
\hline 660100 & WD41403 & PYE/MF1 & $2005 / 02 / 01$ & operational \\
\hline 880102 & WD30270 & TWP/CF1 & $2003 / 11 / 30$ & operational \\
\hline 880105 & WD30880 & TWP/CF3 & $2002 / 07 / 16$ & operational \\
\hline 880106 & WD30881 & SGP/CF1 & $2000 / 07 / 02$ & operational \\
\hline 880107 & WD30882 & TWP/CF2 & $2002 / 11 / 12$ & operational \\
\hline
\end{tabular}

\section{Near-Real-Time Data Plots}

Available at DQ HandS (Data Quality Health and Status).

\section{Data Description and Examples}

See YES Cloud Cover Products and YES Imaging Product Demos. 


\subsection{Data File Contents}

The following datastreams produced by the TSI are available from the ARM Archive:

- $\quad$ tsiskycover - fractional sky cover and sun obscuration by cloud

- $\quad$ tsiskyimage - hemispheric sky image (JPEG)

- tsimovie - daily movie of hemispheric sky images (MPEG)

- tsicldmask - processed fractional sky cover image (PNG).

ARM netCDF file header descriptions may be found at TSI Data Object Design.

\subsubsection{Primary Variables and Expected Uncertainty}

Visual record of sky conditions.

Fractional sky cover (clear, thin, and opaque amounts).

Sun obscuration by cloud (sunshine meter).

Table 2. Primary Variables

\begin{tabular}{|l|l|l|}
\hline Variable Name & Quantity Measured & Unit \\
\hline percent.opaque & Percent opaque cloud & percent \\
\hline percent.thin & Percentage thin cloud & percent \\
\hline sunny & Sunshine meter & none \\
\hline
\end{tabular}

\subsubsection{Definition of Uncertainty}

See ARM Technical Report “Total Sky Imager Model 880 Status and Testing Results.”

\subsubsection{Secondary/Underlying Variables}

Table 3. Secondary Variables

\begin{tabular}{|l|l|l|}
\hline \multicolumn{1}{|c|}{ Variable Name } & \multicolumn{1}{c|}{ Quantity Measured } & \multicolumn{1}{c|}{ Unit } \\
\hline solar.altitude & Sun altitude above horizon & degrees \\
\hline solar.azimuth & Solar azimuth angle & degrees \\
\hline region.zenith.count.thin & Pixel count: number thin in zenith circle & pixels \\
\hline region.zenith.count.opaque & Pixel count: number opaque in zenith circle & pixels \\
\hline region.zenith.count & Pixel count: number total in zenith circle & pixels \\
\hline region.sun.count.thin & Pixel count: number thin in sun circle & pixels \\
\hline region.sun.count.opaque & Pixel count: number opaque in sun circle & pixels \\
\hline region.sun.count & Pixel count: number total in sun circle & pixels \\
\hline region.horizon.count.thin & Pixel count: number thin in horizon area & pixels \\
\hline region.horizon.count.opaque & Pixel count: number opaque in horizon area & pixels \\
\hline region.horizon.count & Pixel count: number total in horizon area & pixels \\
\hline count.sub.proczen & Pixel count: number total between horizon and processed circle & pixels \\
\hline count.opaque & Pixel count: number total opaque & pixels \\
\hline
\end{tabular}


Table 3. (cont'd)

\begin{tabular}{|l|l|l|}
\hline \multicolumn{1}{|c|}{ Variable Name } & \multicolumn{1}{c|}{ Quantity Measured } & Unit \\
\hline count.thin & Pixel count: number total thin & pixels \\
\hline count.box & Pixel count: box, outside mirror area & pixels \\
\hline count.sky & Pixel count: number total in processed circle & pixels \\
\hline count.unknown & Pixel count: number total indeterminant & pixels \\
\hline count.mask & Pixel count: camera and sun strip mask & pixels \\
\hline count.sub.horz & Pixel count: number below horizon in image & pixels \\
\hline
\end{tabular}

\subsubsection{Diagnostic Variables}

Table 4. Diagnostic Variables

\begin{tabular}{|l|l|l|}
\hline Variable Name & \multicolumn{1}{|c|}{ Quantity Measured } & \multicolumn{1}{c|}{ Unit } \\
\hline time_offset & Time offset from base_time & seconds \\
\hline sun.strength & Relative 'strength' of direct sun & none \\
\hline
\end{tabular}

\subsubsection{Data Quality Flags}

Most fields contain a corresponding, sample-by-sample, automated quality-check field in the b1 level datastreams. These flags are named qc_<fieldname $>$. For example, the percent.opaque field also has a companion qc_percent.opaque field. Possible values for each sample of the qc_<fieldname> are shown in the table below.

Table 4. Data Quality Flags

\begin{tabular}{|c|l|}
\hline Value & \multicolumn{1}{c|}{ Definition } \\
\hline 0 & All QC checks passed \\
\hline 1 & Sample contained 'missing data' value \\
\hline 2 & Sample was less than prescribed minimum value \\
\hline 3 & Sample failed both 'missing data' and minimum value checks \\
\hline 4 & Sample greater than prescribed maximum value \\
\hline 5 & Sample failed both minimum and maximum value checks (highly unlikely) \\
\hline 7 & Sample failed minimum, maximum and missing value checks (highly unlikely) \\
\hline 8 & $\begin{array}{l}\text { Sample failed delta check (change between this sample and previous sample } \\
\text { exceeds a prescribed value }\end{array}$ \\
\hline 9 & Sample failed delta and missing data checks \\
\hline 10 & Sample failed minimum and delta checks \\
\hline 11 & Sample failed minimum, delta and missing value checks \\
\hline 12 & Sample failed maximum and delta checks \\
\hline 14 & Sample failed minimum, maximum and delta checks \\
\hline 15 & Sample failed minimum, maximum, delta and missing value checks \\
\hline
\end{tabular}


The following are the current definitions for the minimum and maximum thresholds:

Table 5. Data Quality Thresholds

\begin{tabular}{|l|l|r|r|}
\hline \multicolumn{1}{|c|}{$\begin{array}{c}\text { Field } \\
\text { Name }\end{array}$} & Units & Min & \multicolumn{1}{c|}{ Max } \\
\hline percent.opaque & percent & 0 & 100 \\
\hline percent.thin & percent & 0 & 100 \\
\hline sunny & none & 0 & 1 \\
\hline sun.strength & none & -100 & 100 \\
\hline solar.altitude & degrees & -90 & 90 \\
\hline solar.azimuth & degrees & 0 & 360 \\
\hline region.zenith.count.thin & pixels & 0 & 101400 \\
\hline region.zenith.count.opaque & pixels & 0 & 101400 \\
\hline region.zenith.count & pixels & 0 & 101400 \\
\hline region.sun.count.thin & pixels & 0 & 101400 \\
\hline region.sun.count.opaque & pixels & 0 & 101400 \\
\hline region.sun.count & pixels & 0 & 101400 \\
\hline region.horizon.count.thin & pixels & 0 & 101400 \\
\hline region.horizon.count.opaque & pixels & 0 & 101400 \\
\hline region.horizon.count & pixels & 0 & 101400 \\
\hline count.sub.proczen & pixels & -1 & 101400 \\
\hline count.opaque & pixels & -1 & 101400 \\
\hline count.thin & pixels & -1 & 101400 \\
\hline count.box & pixels & -1 & 101400 \\
\hline count.sky & pixels & -1 & 101400 \\
\hline count.unknown & pixels & -1 & 101400 \\
\hline count.mask & pixels & -1 & 101400 \\
\hline count.sub.horz & pixels & -1 & 101400 \\
\hline & & & \\
\hline
\end{tabular}

\subsubsection{Dimension Variables}

Table 6. Dimension Variables

\begin{tabular}{|l|l|l|}
\hline Variable Name & Quantity Measured & Unit \\
\hline base_time & Base time in Epoch & seconds \\
\hline lat & north latitude & Degrees \\
\hline lon & east longitude & degrees \\
\hline alt & altitude & meters above Mean Sea Level \\
\hline
\end{tabular}

\subsection{Annotated Examples}

This section is not applicable to this instrument.

\subsection{User Notes and Known Problems}

TSI retrievals of fractional sky cover are valid for solar elevation angles of 10 degrees or greater. 


\subsection{Frequently Asked Questions}

See YES TSI FAQs.

\section{Data Quality}

\subsection{Data Quality Health and Status}

The following links go to current data quality health and status results:

- DQ HandS (Data Quality Health and Status)

- $\quad$ NCVweb for interactive data plotting using.

The tables and graphs shown contain the techniques used by ARM's data quality analysts, instrument mentors, and site scientists to monitor and diagnose data quality.

\subsection{Data Reviews by Instrument Mentor}

The system is frequently monitored for continued operation. Sky cover retrievals are monitored and spot checked by comparison of the sky images and their corresponding "cloud decision images." This process cannot be automated. A visual inspection detects any periods that are not optimal, and these periods are reprocessed. Updated files are sent to the ARM Archive.

\subsection{Data Assessments by Site Scientist/Data Quality Office}

All DQ Office and most site scientist techniques for checking have been incorporated within DQ HandS and can be viewed there.

A comparison between the fractional sky cover data included in the Shortwave Flux Analysis ValueAdded Product (VAP), derived from the broadband shortwave irradiance, and in the TSI-retrieved total sky cover is planned.

\subsection{Value-Added Procedures and Quality Measurement Experiments}

Many of the scientific needs of the ARM Program are met through the analysisby analyzing and processing of existing data products into "value-added" products or VAPs. Despite extensive instrumentation deployed at the ARM CART sites, there will always be quantities of interest that are either impractical or impossible to measure directly or routinely. Physical models using ARM instrument data as inputs are implemented as VAPs and can help fill some of the unmet measurement needs of the program. Conversely, ARM produces some VAPs not in order to fill unmet measurement needs, but instead to improve the quality of existing measurements. In addition, when more than one measurement is available, ARM also produces “best estimate” VAPs. A special class of VAP called a Quality Measurement Experiment (QME), which is a special class of VAP, does not output geophysical parameters of scientific interest. Rather, a QME adds value to the input datastreams by providing for continual quality assessments continuous assessment of the quality of the input data based on internal consistency checks, comparisons between independent similar measurements, or comparisons between 
measurements with modeled results, and so forth. For more information see, the VAPs and QMEs web page.

In addition, VAP information is derived from inferred fractional sky cover and sunshine duration. A QME comparison with observer reports and with whole sky imager (WSI) sky cover retrievals are underway as part of the Southern Great Plains (SGP) Central Facility (CF) system evaluation.

\section{Instrument Details}

\subsection{Detailed Description}

\subsubsection{List of Components}

The YES Total Sky Imager Model TSI-660 is an automatic, full-color sky imager system that provides real-time processing and display of daytime sky conditions. An image-processing program running on a PC workstation captures images via TCP/IP at a 30-sec sampling interval and saves them to JPEG files that are analyzed to infer both fractional sky cover and sunshine duration.

For more information, visit YES Total Sky Imager.

\subsubsection{System Configuration and Measurement Methods}

Images from the sky are captured via a solid-state charge-coupled device looking downward onto a heated, rotating hemispherical mirror. A shadowband on the mirror blocks the intense direct-normal light from the sun, thereby protecting the imager optics. An image-processing algorithm captures and displays the images.

The TSI is a daytime imager. Once the sun rises above a user-selectable minimum solar zenith angle, image acquisition begins. The analysis step first masks out obstructions - the imager, its arm, and the sunblocking band. Fractional sky cover is determined by a processing algorithm that examines the color relationships of the remaining image pixels to infer whether the pixel represents clear sky or thin or opaque cloud. In addition, the differential of brightness along the sun blocking band is analysed to infer if the sun is blocked by cloud or not, i.e., a sunshine meter. 


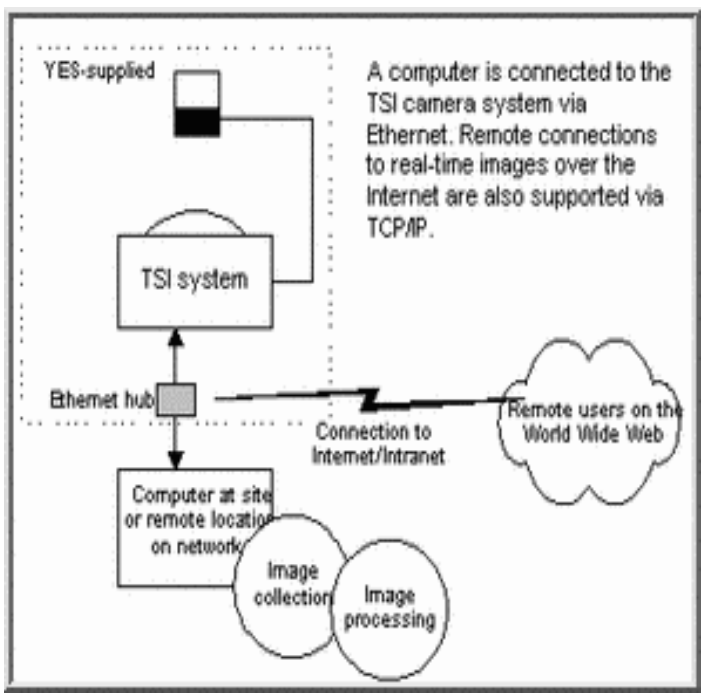

\subsubsection{Specifications}

Figure 1. TSI Communications diagram

Table 7. Instrument Specifications

\begin{tabular}{|c|c|}
\hline Parameter & Value \\
\hline Image Resolution: & 352 x 288 color, 24-bit JPEG format \\
\hline Sampling rate: & Variable, with max. of one image every $30 \mathrm{sec}$ \\
\hline Operating Temperature: & $-40^{\circ} \mathrm{C}$ to $+44^{\circ} \mathrm{C}$ \\
\hline Weight/Size: & $\begin{array}{l}\text { Approx.70 lbs.(32 kg); dims: 20.83”x18.78”; height is } \\
\text { 34.19”; mounts on } 16.75 \times 12 ” 1 / 4-20 \text { bolt square }\end{array}$ \\
\hline Power Requirements: & $\begin{array}{l}\text { 115/230 VAC; mirror heater duty cycle varies with air } \\
\text { temperature: } 560 \mathrm{~W} \text { with heater on / } 60 \mathrm{~W} \text { off }\end{array}$ \\
\hline Software: & Image application supports MS-Windows ${ }^{\circledR}$ \\
\hline Data Storage: & Local workstation disk \\
\hline Communication: & 10BaseT/RJ45 (15m) \\
\hline
\end{tabular}

\subsection{Theory of Operation}

Images from the sky are captured via a solid state CCD imaging camera that looks downward on a heated hemispherical mirror. The mirror images the hemisphere over the system into the lens, and has a solarephemeris guided shadowband to block the intense direct-normal radiation from the sun. An imageprocessing program running on a user-provided PC workstation captures images via TCP/IP at a userdefined sampling rate and saves them to JPEG files for analysis. The analysis software first masks out known obstructions -- the camera, its arm, and the sun-blocking shadowband. The raw color image is analyzed for fractional cloud cover, and both are stored as files.

\subsection{Calibration}

\subsubsection{Theory}


Sky cover processing limits are set by the instrument mentor, based on experience and tailored to human observations.

\subsubsection{Procedures}

This section is not applicable to this instrument.

\subsubsection{History}

This section is not applicable to this instrument.

\subsection{Operation and Maintenance}

\subsubsection{User Manual}

This section is not applicable to this instrument.

\subsubsection{Routine and Corrective Maintenance Documentation}

$\underline{\text { SGP Preventative Maintenance Procedure }}$

TWP Operating Procedure

\subsubsection{Software Documentation}

YES TSI Manager

\subsubsection{Additional Documentation}

This section is not applicable to this instrument.

\subsection{Glossary}

Sky cover - The amount of the hemispheric field-of-view of the sky from the viewpoint of an observer standing on the surface that contains "cloud," generally expressed in percent.

Also see ARM Glossary.

\subsection{Acronyms}

JPEG: Joint Photographic Experts Group compressed digital image format

PNG: Portable Network Graphics digital image format

TXT: ASCII text format

YES: Yankee Environmental Systems

Also see ARM Acronyms and Abbreviations. 


\subsection{Citable References}

Kassianov, E, and C Long. 2003. "Paired Ground-Based Hemispherical Observations for Cloud Base Height Estimation.” In Thirteenth Atmospheric Radiation Measurement (ARM) Program Science Team Meeting, Ed. by D Carrothers, U.S. Department of Energy, Richland, WA.

Kassianov, E, C Long, and J Christy. 2004. “ARM Cloudiness Intercomparison IOP 2003 Analysis: Cloud Base Height.” Presented at Fourteenth ARM Science Team Meeting, Albuquerque, NM.

Kassianov, E, CN Long, M Ovtchinnikov, and J Christy. 2004. "Cloud properties retrievals from surface hemispherical observations.” Presented at International Radiation Symposium 2004 IRS, Busan, Korea.

Kassianov, E, CN Long, and M Ovtchinnikov. 2005. "Cloud sky cover versus cloud fraction: whole-sky simulations and observations.” Journal of Applied Meteorology 44: 86-98.

Long, CN, and JJ DeLuisi. 1998. "Development of an Automated Hemispheric Sky Imager for Cloud Fraction Retrievals.” In Proceedings 10th Symposium on Meteorological Observations and Instrumentation, January 11-16, 1998, Phoenix, AZ.

Long, CN, DW Slater, and T Tooman. 2001. Total Sky Imager Model 880 Status and Testing Results. ARM Technical Report ARM TR-006, U.S. Department of Energy, Washington, D.C. 